\title{
Public Awareness of the National Health Insurance Scheme (NHIS) among Patients accessing Healthcare in Supreme Faith Hospital, Ado-Ekiti, Nigeria
}

\author{
Article by Pius Izundu Okpoko \\ PhD in Public Health, Texila American University \\ E-mail: supfaith2000@yahoo.com
}

\begin{abstract}
Objective - To determine the public awareness of the National Health Insurance Scheme (NHIS) among patients accessing health care in Supreme Faith Hospital, Ado-Ekiti, Nigeria.

Study design and Setting - A cross-sectional study design that made use of quantitative survey method involving data collection and analysis.

Participants - 120 voluntary adults who access health care services at Supreme Faith Hospital, Ado-Ekiti, Nigeria.

Method - A semi-structured questionnaire was administered to participants who also consented to the survey. A cross-sectional study was deemed fit for this research because it enables any desired data to be collected at one point in time.

Results - The study revealed that a greater number of respondents i.e. 82 (68.3\%) were aware of the existence of the National Health Insurance Scheme (NHIS) but only 38(31.7\%) were enrolees in a hospital setting which is accredited to providing health care services under NHIS. There were more females (64.2\%) than males (35.8\%) among the respondents. A greater number of respondents were educated; Secondary (36.7\%) and Tertiary education (48.3\%), while Primary education (8.0\%) and none/others (10.0\%) were much lesser. There was weak statistical significant finding between education and awareness of NHIS $(p=0.045)$.

Conclusions - The awareness of NHIS was high among patients who were accessing health care services in an accredited facility in Nigeria. However, the number of enrolees among them was much lesser than expected. It is recommended that effort should be geared towards improving the rate of enrolment process, especially in the face of the heavy burden of out-of-payment expenditure in health care.
\end{abstract}

Keywords: Enrolee, Healthcare, Health insurance, Nigeria, Out-of-pocket payment, Services.

\section{Introduction and background}

The history of health insurance dates back to 1883 in Germany when Emperor Otto Von Bismarck enacted the mandatory legislation on the 'sickness funds' for working Germans. Since then different types of health insurance have continued to evolve among various countries of the world.

Payment for health care services can take different forms. For example, out-of-pocket payment, Insurance (which can be made by private or government organisation), and free health service scheme which is mainly carried out by the government or religious bodies. In developing world, out-of-pocket payment for health care service takes the highest degree (Spaan, Mathijssen, Tromp, et al, 2012). This discourages health care accessibility and utilisation particularly among financially less privileged group in the society. The World Health Organisation (WHO) considers health insurance scheme a worthy means for making universal health care coverage a reality (WHO, 2010). Nigeria has over 80 percent of her population who rely heavily on out-of-pocket expenditure for individuals and family members.

Corporate organisations pay for their work force through arrangement with private hospitals on retainer ship basis, although recently some of them are gradually embracing one form of Health insurance scheme or the other. Spaan, Mathijssen, Tromp, et al, (2012) 
emphasise that the heavy burden and challenges posed to individuals by out-of-pocket payment for health care services have discouraged accessibility to health care facilities in Sub-Saharan Africa. Health insurance scheme which serves as a better option is yet to gain solid ground in most developing countries.

In an attempt to address the burden of out-of-pocket payment for health care services, the Nigerian government under the leadership of former President Olusegun Obasanjo, launched the National Health Insurance Scheme (NHIS) on $6^{\text {th }}$ June 2005. The commencement of services to enrolees, however, started in September 2005 (NHIS, 2014). The initial enrolees under the scheme were majorly from the formal sector which comprises of the public sector, the Armed forces and Allied services. The past two years has witnessed additional registration of organised private sector, students of tertiary institutions and voluntary contributors.

As at 2013, NHIS has only achieved registration of about 5 million enrolees in a country with an estimated population of over 160 million people since its inception. Has the scheme created sufficient public awareness to encourage individuals to come on board or are there other impediments delaying increasing surge in the number of enrolees in a country with serious burden of out-of-pocket expenditure in health care industry.

The objective of the study is to determine the public awareness of the National Health Insurance Scheme (NHIS) among patients accessing health care in Supreme Faith Hospital, Ado-Ekiti, Nigeria.

\section{General considerations}

\section{History about NHIS}

The idea to build a national health insurance that would greatly address of out-of-pocket payment for health care services was muttered in 1962 after Nigerian independence from her colonial master. Various governments that succeeded the then government attempted taking steps into actualising the dream of a national health insurance scheme but none of them did any palpable work to realise the vision.

To worsen the situation, the country was forced into military detector ship that lasted for over 3 decades. None of the military Head of States took giant stride into actualising a health insurance for a teaming Nigeria population. It was not until the democratically elected government under the leadership of former president Olusegun Obasanjo launched the very laudable National Health Insurance Scheme (NHIS) on $6^{\text {th }}$ June, 2005.

The scheme was established under Acts 35 of 1999 by the federal government of Nigeria with the singular aim of providing easy access to health care for all Nigerians (irrespective of age) at an affordable cost through various prepayment systems (NHIS, 2004). The journey from 2005 till date to achieve a wider coverage of the population and give succour to Nigerian citizens through NHIS has rather been a daunting task.

\section{Benefit packages}

The provision of health care services by the National Health Insurance Scheme (NHIS) is through the pooling of fund from the participating governmental and non-governmental bodies. This is different from the situation witnessed in the National Health System (NHS) in Britain where the government uses tax-payers money to operate the system. The contributions made into NHIS cover different dimensions of health care benefits for the enrolees including the employee, a spouse and four biological children who are under 18 years of age (NHIS, 2014). However, an additional payment by the principal beneficiary can be made under a defined payment system for more dependants or his biological children who are above 18 years.

The benefit packages for NHIS enrolees include:

- out-patient care for enrolees

- . Approved drugs as prescribed by the physician, pharmaceutical care and laboratory / diagnostic test.

- Maternity care which extends to four live births. 
- Preventive care like immunization (under EPI), health education, antenatal care, postnatal care, and family planning.

- Consultation under secondary care with specialists.

- Hospital admission not exceeding a cumulative 15 days per year.

- Ophthalmological examinations and care but without the provision of spectacles and contact lenses for enrolees.

- Preventive dental care and pain relief.

- A range of prosthesis which is limited to artificial limbs made in Nigeria (NHIS, 2014).

Other extended benefits to the enrolees under the NHIS include referral from one hospital to another depending on the nature of severity of the health problem. For example, a referral of patient from a primary to a secondary health care facility, or a secondary to a tertiary health care institution. NHIS utilises strategic health communication in its rural community based programmes to facilitate social change.

There are obvious exclusions that are well defined by NHIS in her service to enrolees. They include (but not limited to) management of infertility, organ transplant, oversee treatment of chronic health conditions, etc.

\section{Operation of NHIS under the current formal sector social health insurance programme}

The formal sector social Health Insurance programme under NHIS is a social health security system which is designed to take care of employees' health care need from funds created by pooling the various contributions of employees and employers in the formal sector (NHIS, 2014). It is worth noting that the formal sector consists of the public sector, organised private sector, Armed forces, police and allied service, students of tertiary institution in Nigeria and voluntary contributors.

The contributions made into the common fund are earning-related i.e. contributions are made depending on the basic salary of the enrolee. A total of $15 \%$ of the employees' basic salary is contributed into the common pool. The employer pays $10 \%$ while the employee pays $5 \%$. An additional payment is made by an enrolee when accessing health care services. This time, only $10 \%$ of the total cost of drugs dispensed (excluding consultation) is paid to the health care facility.

The market structure seen in NHIS does not follow a normal market pattern in structure, conduct and performance (SCP) as witnessed in other industries. However there exists interplay between monopolistic competition and oligopoly. Moreover, health care market presents difficulty in measuring its product and cost (TAU, 2014).

NHIS has the characteristics of a matrix organisation. It is a horizontally based organisation which is programme focused rather than position-oriented. (TAU, 2014). There are different tentacles used by NHIS to provide health care services to enrolees and also judiciously manage the available resources. The Health Maintenance Organisation (HMO) receives money from NHIS and disburses it, in form of capitation payment for primary care, to Health Care Providers (HCP). Additionally, the HMO pays fee-for-service to HCP for secondary and tertiary health care services. There is a reciprocal accountability on the part of the HPC to give regular information to the HMO about enrolees' usage of health care facilities. The NHIS oversees the activities of the HMO and HCP, and regularly monitors patient satisfaction with health care services.

\section{Health insurance programme in sub-saharan africa}

The burden of ill health especially from communicable diseases and emerging and reemerging diseases in the face of heavy burden of out-of-pocket payment modality in the subSaharan Africa, there was a singular need to establish health insurance scheme in countries in the region. Some countries took steps, some years ago to introduce health insurance scheme into their national life. However, the journey towards its full realisation in those countries was 
challenging and daunting. Problems of poverty, wars and consequential displacement of individuals and communities made it difficult to organise a vibrant health insurance scheme. Liberia, for example, is still recovering from long years of civil war. There is no well organised and affordable health insurance scheme in place. The available ones are deeply into for-profit business (Pacific Prime, 2014).

Ghana smoothly kick-started her health insurance scheme in 2004 and it has presently recorded a success of about 60 percent national coverage (Ghana-NHIS, 2010). South Africa has both private and public health care systems. The vast majority of the population access the public health care system, while the wealthiest 20 percent of the population access their health care need in the private system. The South African public health care system is chronically understaffed and underfunded. There is no national health insurance scheme in place. However, the present government is taking steps towards actualising a national health insurance to cater for the health need, especially, of the low and middle class. Meanwhile, the Nigerian health insurance scheme has only recorded about 5 percent national coverage since its inception in 2005. Other countries in the sub-Saharan Africa have their various levels in the organisation of health insurance programmes for their citizenry.

\section{Methods}

\section{Study setting}

The study was done at the out-patient department of Supreme Faith Hospital, Ado-Ekiti, Nigeria. The hospital is an accredited facility by the National Health Insurance Scheme (NHIS) for the purpose of providing health care services to the enrolees under the scheme.

\section{Ethical clearance}

Permission was obtained from the Hospital Ethics committee, and written consent (in form of a 'ticked consent') was also obtained from the participants after due explanation of the survey and assurance of anonymity and confidentiality.

\section{Study design}

This was a cross-sectional survey that made use of pre-tested questionnaire which was administered to volunteers.

\section{Inclusion criteria}

Adults attending the clinic who gave consent

Conscious and alert patients who could answer questions adequately

\section{Exclusion criteria}

Very young children were excluded from the study

Severe emergencies, including unconscious patients, were excluded

Those with severe mental illness were also excluded.

\section{Sample size estimation}

This was estimated to be 120 . The sample size was calculated using the formula (Araoye, 2003):

$$
\mathrm{N}=\mathrm{Z}^{2} \mathrm{pq} / \mathrm{d}^{2}
$$

Where $\mathrm{z}=$ standard normal deviation which is usually set at 1.96 and corresponds to the 95\% confidence level.

$\mathrm{P}=$ the proportion in the target population estimated to have a particular characteristic i.e. prevalence here $50 \% . \mathrm{d}=$ degree of accuracy desired which is usually set at 0.05 . 


\section{Data collection and analysis}

The data collection was done by the researcher and trained assistants within the month of March, 2014. The content of the questionnaire was carefully translated into local language to those who could not read English without altering the meaning of each question. The questionnaires were collected from the participants immediately after answering them to avoid loss on transit. The information obtained from respondents was coded for easy translation into data. Data analysis was done using SPSS version 16.

\section{Results}

There were 120 returned and analyzable questionnaires. Table 1 is a representation of respondents' biosocial characteristics. The modal age group in this study was 21-40 years (29.2\%). There were more females (64.2\%) than males (35.8\%) in the study. A greater percentage of the respondents were married $(60.0 \%)$, others were single $(28.3 \%)$, separated (8.3\%), divorced $(0.8 \%)$, and widowed (2.5\%). A total number of 8 (6.7\%) respondents only had primary education, 44 (36.7\%) secondary education, 58 (48.3\%) tertiary, 8 (6.7\%) had no formal education, while $2(1.7 \%)$ did not indicate their educational status. On the respondents' employment status, 50 (41.7\%) were employed while 31 (25.8\%) were not employed. The students among them were 24 (20.0\%) and the apprentices were $6(5.0 \%)$, while the rest did not specify their employment status (5.0\%) or decided to remain silent on it (2.5\%).

Table 1 Biosocial data of respondents.

\begin{tabular}{lcllll}
\hline Variables & Frequency & Percentage & Variables & Frequency & Percentage \\
\hline AGE & & & $\begin{array}{l}\text { EMPLOYMENT } \\
\text { STATUS }\end{array}$ & & \\
GROUP & & & No response & 3 & 2.5 \\
No response & 4 & 3.3 & Employed & 50 & 41.7 \\
$<=20$ & 10 & 8.3 & Not employed & 31 & 25.8 \\
$21-30$ & 35 & 29.2 & Student & 24 & 20.0 \\
$31-40$ & 29 & 24.4 & Apprentice & 6 & 5.0 \\
$41-50$ & 25 & 20.8 & Others & 6 & 5.0 \\
& & & & & 100.0 \\
$51-60$ & 13 & 10.8 & Total & & \\
61 and above & 4 & 3.3 & & & \\
Total & 120 & 100.0 & & & \\
SEX & & & & & \\
Male & 43 & 35.8 & & & \\
Female & 77 & 63.2 & & & \\
Total & 120 & 100.0 & & & \\
MARITAL STATUS & & & \\
Single & 34 & 28.3 & & \\
Married & 72 & 60.0 & & \\
Separated & 10 & 8.3 & & \\
Divorced & 1 & 0.8 & & \\
Widowed & 3 & 2.5 & & \\
Total & 120 & 100.0 & & \\
PRESENT EDUCATIONAL STATUS & & & \\
No response & 2 & 1.7 & & \\
Primary & 8 & 6.7 & & \\
Secondary & 44 & 36.7 & & \\
Tertiary & 58 & 48.3 & & \\
Others & 8 & 6.7 & & \\
Total & 120 & 100.0 & & & \\
\hline
\end{tabular}


South American Journal of Public Health

Volume 4, Issue 2, 2016

Table 2 contains the information on hospital visits of respondents with mode of payment for medical treatment. The majority of them, 103 (85.8\%), indicated that they had visited hospital for treatment in the past but the rest did not. A far greater percentage of the respondents (65.0\%) accessed health care through out-of- pocket payment modality; only $10.8 \%$ were insured (Table 2(ii)). Others accessed care through free government health care programs $(7.2 \%)$, while a total of $16.7 \%$ did not specify their mode of payment for health care services.

Additionally, on the aspect of NHIS awareness (Table 2), 82 (68.3\%) were aware of NHIS while $38(31.7 \%)$ were not aware. The modal year group was $1-3$ years $(40.0 \%)$. Meanwhile, the information on enrolment into NHIS revealed that only 38 (31.7\%) were enrolled as at the time of this study. Others 82 (68.3\%) were yet to be enrolled into the scheme. Table 3 is the logistic regression model for the study. The Chi-square p-value was 0.045.

Table 2: Hospital visit, awareness, and enrolment under NHIS.

\begin{tabular}{|c|c|c|}
\hline Variables & Frequency & Percentage \\
\hline \multicolumn{3}{|c|}{$\begin{array}{l}\text { Hospital visit of respondents (Have you visited hospital before } \\
\text { for medical treatment?) }\end{array}$} \\
\hline Yes & 103 & 85.8 \\
\hline No & 17 & 14.2 \\
\hline Total & 120 & 100.0 \\
\hline \multicolumn{3}{|c|}{$\begin{array}{l}\text { Hospital visit of respondents (Mode of payment for health } \\
\text { care) }\end{array}$} \\
\hline 0 (no response) & 17 & 14.2 \\
\hline Out-of-pocket payment & 78 & 65.0 \\
\hline Insurance (e.g. NHIS or others) & 13 & 10.8 \\
\hline Free govt. Health care program & 9 & 7.5 \\
\hline Others & 3 & 2.5 \\
\hline \multicolumn{3}{|c|}{ Awareness of NHIS (Are you aware of NHIS?) } \\
\hline Yes & 82 & 68.3 \\
\hline No & 38 & 31.7 \\
\hline Total & 120 & 100.0 \\
\hline \multicolumn{3}{|c|}{$\begin{array}{l}\text { Awareness of NHIS (If yes for how long have You been aware } \\
\text { of it?) }\end{array}$} \\
\hline 0 (no response) & 38 & 31.7 \\
\hline$<1$ year & 20 & 16.7 \\
\hline 1-3years & 48 & 40.0 \\
\hline 4-6years & 9 & 7.5 \\
\hline$>6$ years & 5 & 4.2 \\
\hline Total & 120 & 100.0 \\
\hline \multicolumn{3}{|c|}{ Enrolment under NHIS (Are you an enrolee under NHIS?) } \\
\hline Yes & 38 & 31.7 \\
\hline No & 82 & 68.3 \\
\hline Total & 120 & 100.0 \\
\hline
\end{tabular}


Table 3: Logistic regression: ‘Are you aware of any Health Insurance Program vs. Present educational status'

\begin{tabular}{|c|c|c|c|c|c|c|c|c|}
\hline & & & Present & ducatior & al status & & & Total \\
\hline & & & 0 & $\begin{array}{l}\text { Primar } \\
\mathrm{y}\end{array}$ & $\begin{array}{l}\text { Second } \\
\text { ary }\end{array}$ & Tertiary & $\begin{array}{l}\text { None/ot } \\
\text { hers }\end{array}$ & \\
\hline Are you & Yes & & 1 & 2 & 34 & 39 & & 80 \\
\hline aware of any & & \% within & $50.0 \%$ & $25.0 \%$ & $77.3 \%$ & $67.2 \%$ & $50.0 \%$ & $66.7 \%$ \\
\hline Health & & Present & & & & & & \\
\hline Insurance & & educational & & & & & & \\
\hline & No & Count & 1 & 6 & 10 & 19 & 4 & 40 \\
\hline & & \% within & $50.0 \%$ & $75.0 \%$ & $22.7 \%$ & $32.8 \%$ & $50.0 \%$ & $33.3 \%$ \\
\hline & & $\begin{array}{l}\text { Present } \\
\text { educational } \\
\text { status }\end{array}$ & & & & & & \\
\hline Total & & & 2 & 8 & 44 & 58 & 8 & 120 \\
\hline & & $\begin{array}{l}\text { \% within } \\
\text { Present } \\
\text { educational } \\
\text { status }\end{array}$ & $100.0 \%$ & $100.0 \%$ & $100.0 \%$ & $100.0 \%$ & $100.0 \%$ & $100.0 \%$ \\
\hline
\end{tabular}

The Chi-square value, $\mathrm{p}=0.045$.
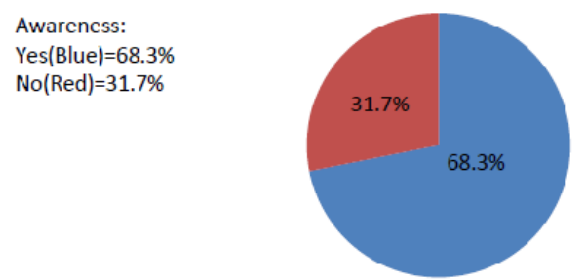

Figure 1: Pie chart representing the awareness of NHIS among the respondents.

\section{Discussion}

In consideration of the daunting challenge facing both the patients who access health care facilities through out-of-pocket payment and the Providers of health care who need to continue their practice despite the present economic downturn, this study has painstakingly assessed the public awareness of the National Health Insurance Scheme (NHIS) among patients accessing health care in Supreme Faith Hospital, Ado-Ekiti, Nigeria. Ado-Ekiti is the Capital of Ekiti State in the south west geopolitical zone of Nigeria.

There were more females (64.2\%) than males (35.8\%) among the respondents in the study. This could be as a result of improved uptake of antenatal, post-natal, and other maternal/child care aspects of health care services. Also, in support of this, was the greater number of respondents in the various reproductive age groups viz 21-30 years (29.2\%), 31-40 years (24.2\%) and 41-50 years (20.8\%). Other age groups did not individually record above $10.8 \%$. Additionally, 'married' respondents (60.0\%) were indicated as the highest among the various marital statuses in the study.

A greater number of respondents were educated; Secondary (36.7\%) and Tertiary education (48.3\%). This was against the number of respondents under Primary education (6.7\%), none (6.7\%) and undecided (1.7\%). However, the association between educational level and awareness of NHIS was weakly statistically significant $(\mathrm{p}=0.045)$. In the study done by Sabouhi et al (2011), educational level and awareness were statistically significant, although the study was not particularly on NHIS.

Worthy of note was the greater number of respondents (68.3\%) who were aware of NHIS compared with those who were not aware (31.7\%). Out of this (those aware) about 56.7\%, 
only got to know about NHIS for the past 3 years. This reveals that increasing publicity of the Scheme must have been put in place for the past 3 years. Earlier studies done within the South west geopolitical zone of Nigeria after few years of the inception of NHIS, reported high levels of awareness. Omosehin et al. (2006) reported 99.5\% awareness among respondents in the study, while Sanusi and Awe (2009) had $87 \%$ awareness. The study by Omosehin et al. (2006) was on health care providers of selected health care facilities in Lagos. Sanusi and Awe (2009) researched on health care consumers residing at Ibadan, Nigeria. Both cities are urban areas in Nigeria and are more developed than the area of the present study. Meanwhile, the present study was done on patients who were accessing health care services from an accredited health care facility in Ado-Ekiti, Nigeria. Although the awareness was high among respondents, regrettably only $31.7 \%$ of respondents were enrolled under the Scheme as at the time of data collection.

\section{Conclusion}

The awareness of NHIS was high among patients who were accessing health care services in an accredited facility in Nigeria. However, the number of enrolees among them was much lesser than expected. A greater number of respondents still rely on out-of-pocket expenditure for payment for health care services. It is recommended that effort should be geared towards improving the rate of enrolment process, especially in the face of the heavy burden of out-ofpayment expenditure in health care.

\section{Recommendations}

(1) There is still a significant number of Nigerians who are not under any health insurance coverage. Therefore, NHIS management should be encouraged by the government to improve on enrolment of Nigerians into the Scheme for wider coverage.

(2) Further research on this topic should be encouraged by using more in-depth approach through qualitative research method to uncover other issues which may not be touched by a quantitative study.

\section{References}

[1.] Araoye, M. (2003) Research Methodology with statistics for Health and Social Sciences. Ilorin: Nathadex publishers.

[2.] Awosika, L. (2005) Health Insurance and Managed care in Nigeria, [Online]. Available from: http://indexmedicus.afro.who.int/iah/fulltext/health\%20insurance.pdf (Accessed: 8 April 2014).

[3.] Ghana National Health Insurance Scheme (2010) National Health Insurance Scheme (NHIS) joint learning network, [Online]. Available at:

http://jointlearningnetwork.org/content/national-health-insurance (Accessed: 30 March 2014).

[4.] National Health Insurance Scheme (2014) NHIS guidelines and benefit package, [Online]. Available at: http://nhis.gov.ng (Accessed: 1 April 2014).

[5.] Omosehin, O., Odeyemi, K. A., Onajole, A. T. and Ogunnowo, B. E. (2006) Awareness and acceptance of the National Health Insurance Scheme among Health care providers in Urban local governments in Lagos State, Journal of Clinical Sciences,vol.6,No.1

[6.] Pacific Prime (2014) Liberia Health Insurance, [Online]. Available at:

http://www.pacificprime.com/country/africa/liberia-health-insurance-pacific-prime-

international/ (Accessed: 30 March 2014).

[7.] Sabouhi, F., Babaee, S., Naji, H., and Zadeh, H. (2011) Knowledge, awareness, attitudes and practice about hypertension in hypertensive patients referring to public health care centers in Khoor \& Biabanak , Iran J Nurs Midwifery Res. 2011 Winter; 16(1): 34-40. [Online]. Available at: http://www.ncbi.nlm.nih.gov/pmc/articles/PMC3203297/ (Accessed: 13 April 2014). 


\section{South American Journal of Public Health}

Volume 4, Issue 2, 2016

[8.] Sanusi, R. A. and Awe, A. T. (2009) Perception of National Health Insurance Scheme (NHIS) by Health care consumers in Oyo State, Nigeria, Pakistan Journal of Social Sciences, Vol.6,issue1,pp48-53.

[9.] Spaan, E., Mathijssen, J., Tromp, N., McBain, F., Have, A., and Baltussen (2012) the impact of health insurance in Africa and Asia: a systematic review. Bulletin of the World Health Organisation 2012; 90:685-692.doi:10,2471/BLT.12.102301.

[10.] Texila American University (2014) Lecture notes on Health Economics. Online; Available at: Texila American University Online Education LMS (Accessed: 24 February 2014).

[11.] World Health Organisation (2010) World health report 2010, Health systems financing the path to universal coverage. Geneva: WHO. 